\title{
Facilitating adult learning: the role of the academic librarian
}

\author{
C. Lyn Currie \\ Published in: Reference Librarian v. 33, nos. 69/70, Spring/Summer 2000, 219-231 \\ (C) Haworth Press
}

\begin{abstract}
This paper considers the instructional role of the academic librarian and examines the contribution adult learning theory makes to the practice of teaching information literacy skills. It explores those principles of effective practice in facilitating adult learning which apply to the teachinglearning transactions in the library. It describes the aim of facilitation as one of encouraging self directed, empowered adults and confirms the role of the academic librarian in facilitating the development of critical thinking, creative problem-solving and informed decision making in adult learners. It also examines the concept of information literacy and how this contributes to adult lifelong learning.
\end{abstract}

Keywords: adult learning, facilitation, self directed learning, information literacy, lifelong learning

Introductory footnote:

C. Lyn Currie BA. Grad Dip Lib. MA.

Head, Education Library

University of Saskatchewan

28 Campus Drive

Saskatoon, Saskatchewan S7N 0X1

Canada

E-mail: currie@sklib.usask.ca 


\section{$\underline{\text { Introduction }}$}

Adult learning theory with its emphasis on developing the skills of the learner rather than transmitting the content of the discipline provides a useful framework for academic librarians involved in teaching information skills. Information skills education based on conceptual and critical thinking models and using the teaching methodologies of adult learning theory is an achievable if challenging objective for academics and librarians in higher education institutions (Wilson, 1994).

Academic librarians have turned in recent times to an examination of the learning process, learning styles of adults and teaching strategies appropriate for adult learners in their efforts to realize the mandate of higher education to "create people who can make informed decisions, creatively problem solve, and think critically and responsively” (Burge, 1989). There is increasing evidence in the literature (Sheridan, 1986; Keenan, 1989; Oberman, 1991) of the application of adult learning theory to the development of user education in libraries. The concept of user education has expanded to encompass training in the skills implicit in Knowles' (1990) definition of the adult independent learner. The notion of information literacy is implied in the critical thinking skills that characterize the independent, self-motivated lifelong learner. Oberman (1991) observed that by 1987 the importance of critical thinking processes in information literacy was well recognized in the bibliographic instruction movement. Conceptual learning, analysis and evaluation of information and the transferability of skills across disciplines have become familiar themes long espoused in the theory and practice of library user education (MacAdam, 1989).

To adopt an adult learner-centred approach implies a move away from totally controlling the teaching and learning situation in the direction of collaboration in an effort to assist learners to become critically 
reflective and independent individuals (Galbraith, 1991). Since adult learners enter the library with intentions, memories and styles of learning the librarian must work to develop helping or trust relationships with them, playing the role of “more capable peer” (Carr, 1986). The librarian assumes the role of a collaborator or facilitator rather than an expert.

\section{Adult Learning Theory}

Knowles' (1980) concept of andragogy has done much to shape the practice of adult education. His andragogical model, the process by which adults learn, is characterized by a mutually respectful, informal, collaborative style of teacher/student relationship which uses experiential techniques and is based on several key assumptions about adult learners:

- $\quad$ they are motivated to learn

- $\quad$ their orientation to learning is life-centred

- $\quad$ experience is the richest resource for their learning

- $\quad$ they have a deep need to be self-directing

- their individual differences increase with age.

The two distinguishing characteristics of adult learning most frequently advanced by theorists are the adult's autonomy of direction when learning and the use of personal experience as a learning resource (Simpson, 1980).

Brookfield (1986) provides a succinct summary of the principles of adult learning specified by adult learning theorists (Gibb, 1960; Miller, 1964; Kidd, 1973; Knox , 1977; Brundage and Mackeracher, 1980; Smith, 1982; and Darkenwald and Merriam, 1982): adults learn throughout their lives, with the negotiations of the transitional stages in the life-span being the immediate causes and motives for much of this learning. They exhibit diverse learning styles - strategies for coding information, cognitive 
procedures, mental sets and they learn in different ways, at different times for different purposes. As a rule however they like their learning activities to be problem-centred and to be meaningful to their life situation and they want the learning outcomes to have some immediacy of application. The past experiences of adults affect their current learning, sometimes serving as an enhancement, sometimes as a hindrance. Effective learning is also linked to the adult's subscription to a self-concept of himself or herself as a learner. Finally adults exhibit a tendency towards self-directedness in their learning.

The development of self-directed learning skills is central to Knowles’ model of lifelong learning. He defined these skills as the ability to:

- $\quad$ develop and be in touch with curiosities

- $\quad$ perceive oneself objectively and accept feedback about one’s performance non-defensively

- $\quad$ diagnose one’s own learning needs in the light of models of competencies required for performing life’s roles

- $\quad$ formulate learning objectives in terms that describe performance outcomes

- $\quad$ identify human, material and experiential resources for accomplishing various kinds of learning objectives

- $\quad$ design a plan of strategies for making use of appropriate learning resources effectively

- $\quad$ carry out a learning plan systematically and sequentially

- $\quad$ collect evidence of the accomplishment of learning objectives and have it validated through performance (Knowles, 1990:174).

As self-directed individuals with a certain amount of life experience, adult learners are desirous of learning those things they perceive necessary to help them cope effectively with their real-life situations. The demands of the adult learner are those of self-direction, relevance, usefulness and the opportunity to integrate life-experiences with learning experiences (Keenan, 1989). According to Burge (1998) adult learning is all about construction (how adults create their own framework of knowledge) 
and confusion (when learners attempt to organize a mass of incoming information); achievement, affiliation and acknowledgement (feeling competent and being connected to others); relevance, responsibility and relationships (relating life experiences and personal knowledge to learning, accepting learner responsibility for learning and establishing collaborative relationships which create a climate that allows for talking in order to think, making mistakes, letting go of old ideas and attitudes and being open to anything new) and expression through which the learner is able to see himself perform, hear himself think, compare thoughts and skills to those of his peers and open his mind to feedback.

\section{Facilitating Adult Learning}

Brookfield (1986) identified six principles of effective practice in facilitating adult learning:

- $\quad$ Participation in learning is voluntary

- $\quad$ Effective practice is characterized by respect among participants for each other's self worth

- $\quad$ Facilitation is collaborative with facilitator and learners engaged in a cooperative enterprise

- $\quad$ Praxis is at the heart of effective facilitation - a continual process of activity, reflection, collaborative analysis, further reflection

- $\quad$ Critical reflection is fostered

- $\quad$ Self-directed empowered adults are nurtured.

Adult learning is best facilitated when learners are engaged as participants in the design of the learning, when they are encouraged to be self-directed, when the educator functions as a facilitator rather than a didactic instructor, when the individual learner’s needs and learning styles are taken into account, when a climate conducive to learning is established, when the learner's past experiences are utilized in the classroom and when learning activities are deemed to have some direct relevance or utility to the learner’s circumstances. 
An effective teaching and learning encounter as described by Galbraith (1991) is one which involves a transaction between facilitator and learner that is active, challenging, collaborative, critically reflective and transforming. The essence of the transactional process is to move adult learners toward independence and responsibility for their own learning. The most common elements of the transactional process are collaboration, support, respect, freedom, equality, critical reflection, critical analysis, challenge, risk taking and praxis. Adult learning methods most appropriate to the transactional process include discussion, simulation, learning contracts, inquiry teams, case method, critical incident, and mentoring. Facilitating adult learning requires an understanding that facilitators and learners bring into an educational encounter varying personalities, personal and professional experiences, levels of sophistication and various cultural and ethical backgrounds. Different approaches are necessary within the teaching and learning process because of the diversity, variability and varying levels of expectations of the learners, the subject matter presented and the varying intellectual domains of the learners.

\section{The Facilitator - Characteristics, roles and skills}

The personality characteristics and interpersonal and human relations skills of the facilitator are central to the success of Knowles’ andragogical approach. The attributes of caring, trust and respect are essential characteristics for the facilitator of adult learners. Brookfield (1986) suggests a facilitator should recognize and understand the diversity of adult learners, provide a climate conducive to learning, provide a contextual setting for the exploration of new ideas, skills and resolutions, provide a forum for critical reflection and have the ability to assist adults in the process of learning how to change their perspectives, shift their paradigms and replace their way of interpreting the world. Implementation of these requires the facilitator to be technically proficient in content and instructional planning areas as well as highly competent in interpersonal and human relation skills. 
The best thing the facilitator can do is act as a collaborative colleague in the learning endeavour. By using a collaborative approach to agree on the learning objectives, adult learners can increase their understanding of and commitment to achieving the objectives, understand the relationship between current and desired proficiencies, reflect on questions that need addressing, and acquire a framework for learning how to learn beyond the present program (Knowles, 1980).

The transition from teacher to facilitator of learning requires a shift in role from content transmitter to process manager and involves performing a different set of functions requiring a different set of skills that include relationship building, needs assessment, involvement of learners in planning, linking learners to learning resources and encouraging learner initiative. Adult educators need to be more concerned with learning processes rather than learning products, with the learner first. In adult learning the life experience of learners and their needs for discussion demand that facilitators pay careful attention to dialogue and process. As learning involves moving from one developmental stage to the next, it becomes the role of the facilitator to perceive correctly where the individual exists on the developmental scale and to assist, not only in allowing the learner to master each new stage, but also in challenging the learner to confront the next one (Keenan, 1989).

The facilitator's roles are diverse given the multifaceted nature of adult learning and the settings in which it occurs. The facilitator may be the challenger, role model, mentor, coach, demonstrator, content resource person and learning guide. According to Mackeracher (1996) the facilitator is a very influential component of the learning environment through the provision of guidance, structure, information, feedback, reinforcement and support. The facilitator's role is often regarded as assisting adults to complete learning efforts that they as learners have defined. This view emphasizes the primacy of the learner, grants a substantial measure of control to learners and places learning directly in 
the context of the learners' own experiences. The difficulty in accepting this is that it assumes a high degree of self-knowledge and critical awareness on the part of adult learners. For the educator it is not always easy to accept adults' definitions of needs as the operational criterion for the development of curriculum, design of programs or evaluation of success.

Facilitators of adult learning need to be proficient in the instructional planning components of needs assessment, context analysis, objective setting, organizing learning activities and evaluation if they are to be effective in helping adults learn. Through needs assessment facilitators can review their assumptions about the educational needs of adult learners and be responsive to those needs. Context analysis considers the societal trends and issues. Adult learners have perceptions of standards, expectations and opportunities that are directly related to their purpose for being engaged in the learning exercise. Understanding these allows the facilitator to contribute to decisions on using learning activities to strengthen problem solving, specify mastery levels, and helping learners use educational strategies that enable them to use or deflect influences that encourage or discourage them to learn and apply (Knox, 1986). The way that learning activities are selected and organized must be rational and based on the educational objectives, the adult learner’s characteristics, current proficiency levels and preferred learning styles as well as the facilitator's own perspective and experience.

\section{The Librarian as Facilitator}

The preference in adult education for a facilitative and collaborative role as opposed to an authoritative role of teachers applies well to the teaching learning transactions that occur in libraries and was supported in the findings of a study conducted by Carr (1986) of adult learners in public libraries. He concluded that a relationship based on collaboration, reciprocity, empathy and trust was critical 
between the learner and the librarian. Success was determined by the learner's desire and commitment to learn and the librarian's effectiveness in nurturing self discovery in the learner.

In recognizing and becoming sensitized to the adult learner's need for self-direction and independence the librarian functions much more as a facilitator than an information manager with a shift in emphasis from providing information to offering the learner the ability to see a number of approaches to achieving the predetermined goal. The goal of academic library user education should be to assist users in their efforts to integrate and exploit the power of library resources in their preferred informationseeking styles. By empowering students to master their own research strategies the librarian is reinforcing the individual's need for self-accomplishment and self-direction (Keenan, 1989).

Burge (1991) points out the academic librarian also needs to mediate creatively between the pragmatic world of adult learners and the high technology world of information. The technological shifts towards macro, global-sized networks for information organization and storage may in turn promote a shift toward micro-sized, communal psychological arenas for meeting the achievement and affiliation drives of adult learners. Intelligent use of technology ought to drive librarians towards a more sophisticated approach to the existing strengths, learning goals, living and learning style preferences of adult learners.

\section{Lifelong Learning and Information Literacy}

The publishing of A Nation at Risk in 1983 by the U.S. National Commission on Excellence in Education called for active learning that prepares students for lifelong learning, active citizenship and risk taking. It claimed that through resource based learning students could master information retrieval and evaluation skills that will be useful for learning throughout their lives. They could become information literate (Breivik, 1989). An information literate person was later defined as one who: 
- $\quad$ recognizes the need for information

- recognizes that accurate and complete information is the basis for intelligent decision making

- $\quad$ formulates questions based on information needs

- identifies potential sources of information

- develops successful search strategies

- $\quad$ accesses sources of information including computer-based and other technologies

- evaluates information

- organizes information for practical application

- $\quad$ integrates new information into an existing body of knowledge

- $\quad$ uses information in critical thinking and problem solving (Doyle, 1992).

These information literacy skills of finding, reading, analyzing, interpreting, applying and communicating information are the foundation for living effectively and being employed productively. They require the use of critical thinking skills to focus on an issue or question, analyze arguments, ask clarifying questions, evaluate reliability of sources and examine assumptions (Ennis, 1987).

To acquire the information literacy skills that are essential to lifelong learning and active citizenship learners need to begin by developing more sophisticated information management skills. Breivik (1989) believes that the six elements of a good learning experience will come together only when librarians and faculty cooperate in shifting the focus toward library-based learning. For Breivik a good learning experience is one which imitates reality, is active, individualized, responsive to a variety of learning styles, accommodates constantly changing information and where the environment is least threatening, 


\section{Library Instruction for Information Literacy}

The potential value of library instruction in facilitating integrated learning and the development of lifelong learning skills is receiving more attention in curriculum planning. Library instruction programs have evolved from descriptions of reference sources, to the use of conceptual frameworks and a thorough going application of cognitive theory to library instruction. The importance of providing users with a conceptual foundation for library information seeking has been extolled within library instruction for years. Lancaster (1972) concluded that users encountered the greatest difficulty in conceptualization and formalization of information needs, selection of appropriate terminology and development of search strategies that could exploit the interactive power of online systems. More recent research tends to confirm his early findings. Tuckett and Stoffle (1984) emphasized the central goal of library instruction as self-reliance on the part of library users, to develop those who have the ability to conceptualize the type and scope of information needed to address a problem, envision the steps required to obtain that information, determine the type of sources which would be appropriate, ascertain if such sources exist, rethink either the type and scope of information needed and make judgements about the quality, pertinence and reliability of the information generated through this process.

Oberman (1991) has commented on the shift in focus in library instruction from an initial concern with lower level cognitive objectives on the Bloom (1984) taxonomy of knowledge and comprehension to the highest cognitive objectives of analysis, synthesis and evaluation. Since problem solving is a critical component of successful library research there is now an emphasis on the role that analytical reasoning abilities and problem solving skills play in the process of library research. The use of learning cycles and guided design by Oberman (1982) is one example of library instruction which 
engaged the learner in a series of activities that demanded the use of abstract reasoning abilities to work through a problem related to information research. In this problem-solving approach to user education there is a direct transfer of responsibility from the instructor to the student which clearly incorporates andragogical/collaborative principles (Sheridan, 1986). More recently Shapiro and Hughes (1996) have argued that information literacy should be conceived broadly as a new liberal art that extends from knowing how to use computers and access information to critical reflection on the nature of information itself, its technical infrastructure and its social, cultural and philosophical context. They identify seven dimensions of literacy which enable individuals not only to use information and information technology effectively and adapt to their constant changes but also to think critically about the entire information enterprise and information society. Those dimensions include:

- $\quad$ tool literacy - the ability to understand and use the practical and conceptual tools of current information technology;

- $\quad$ resource literacy - the ability to understand the form, format, location and access methods of information resources;

- $\quad$ social structural literacy - knowing how information is socially situated and produced;

- $\quad$ research literacy - the ability to understand and use the IT-based tools relevant to the work of today’s researcher and scholar;

- $\quad$ publishing literacy - the ability to format and publish research and ideas electronically in textual and multimedia forms;

- $\quad$ emerging technology literacy - the ability to adapt to, understand and make use of the continually emerging innovations in information technology; and

- critical literacy - the ability to evaluate critically the intellectual, human and social strengths, weaknesses, potentials and limits, benefits and costs of information technology (Shapiro and Hughes, 1996). 
Library users need sound conceptual models in order to successfully negotiate complex interactive library systems. With the constant evolution of data access and communication technologies in libraries there is great need for rapid dialogue between library staff and learners. Such dialogue is part of the mediator and educator roles of librarians and may determine, to a large degree, the extent to which the learner develops the necessary critical and analytical skills for independently using information resources and learning effectively.

\section{Library Instruction and the Adult Learner}

Libraries have confronted the question of how to accommodate the varying knowledge, skills, experience and attitudes of adult learners. The pervasiveness and importance of these diverse factors suggest that new approaches to instruction allowing flexibility and alternate learning experiences for individuals according to their learning styles and a mix of approaches to content presentation will be necessary to educate users (King and Baker, 1987). Academic librarians have been limited in their experience shaping instruction to account for adult learning needs since they are often placed in situations with limited time and no control over class composition. As a result their instructional aims are often cognitive rather than affective and behavioural. As Burge (1991) observed, in working with adult learners one is continually confronted with the problem of how to move learners sensitively and consistently out of their "teach me” passive, receptive attitudes and develop in them the skills and desire to take responsibility for their learning. By way of example she asks: how willing are your learners to spend the time needed to learn the skills for independent navigation around the data networks?

Huston and Oberman (1989) advocated the use of collaborative techniques in library instruction claiming adults are best taught by educating them in a manner that engages their personal conceptual 
frameworks and building on their experiential frameworks and reminding them of what they do know. This in recognition that an effective teacher encourages mutual confrontation and collaboration and allows adults to choose what they need to know. Keenan (1989) called for an emphasis to be placed on individualization of teaching and learning strategies since adults bring to any learning environment a greater quantity and a different quality of experience. She suggested such approaches as meeting with small groups, encouraging group discussion allowing students to question and come to an understanding of how and why user education can be beneficial to them and setting up situations which foster peer-helping activities.

Hensley (1991) has effectively argued that learning style and learning transfer theories can enhance the ability of reference staff to provide quality instruction at the reference desk and contribute to the development of a library user's information-seeking skills. A major desired outcome of the reference desk interaction is the ability of the user to transfer what is learned from one interaction to a new situation. Initial learning and retention of that learning is key to the learning transfer process. He advocates matching the reference librarian's interaction with the user's learning style thereby enhancing clear communication, retention of information imparted and ultimate transfer of learning to new situations. Some strategies he proposes include focussing on understanding the information/instructional need from the user's perspective, sequencing responses into segments that create opportunity for further learning and time for the user to engage in the instructional process, awareness of possible shifts in learning style because of stressful or unfavourable conditions for learning, and providing alternative information sources.

Academic librarians have discovered the imperative to actively pursue a balance involving interaction and cooperation among faculty as course planners, librarians as facilitators of research objectives and students as learners (Baker,1989). Many possibilities exist for such cooperation between librarians and 
faculty for improving student learning particularly if librarians assume an active role as facilitators of critical thinking. If the academic librarian suggests alternative sources to a student, encourages a student to consider an author's reputation and expertise, engage students in active dialogue concerning their assumptions and prejudices about a topic, authorities or varying perspectives on an issue offered by different disciplines they are facilitating critical thinking (Gibson, 1989).

\section{$\underline{\text { Conclusion }}$}

Wilson (1994) has argued that a paradigm shift needs to occur if academic libraries are to make assistance to the adult learner the central objective of library service. Through their continuing advocacy of the library as "a vehicle for self transformation through the life span of the individual” (Carr, 1986), and promotion of information literacy for lifelong learning librarians are beginning to manage that paradigm shift thus claiming a niche for the academic library in the development of the adult learner.

The role for the academic librarian involves being a proactive mediator between information and the learner, sensitive and skilled in interviews and consultation, able to provide appropriate learning resources and teach the learner to be independently skilled in using data sources and libraries. Since the process of adult learning involves the learner in critical analysis of information and confident explorations and analyses of their own and other people's knowledge the ultimate question for the academic librarian becomes one of personal agency according to Burge (1991). If the academic librarian wants to be able to select the most appropriate models of teaching (given the characteristics of adult learners), talk the right language with educators, cater for the style differences in cognition and learning and respond empathetically to learners’ affective and cognitive problems without feeling out of depth, future education and training in adult education is advocated. In terms of those societal trends 
affecting the learning and lifestyle preferences of adults the librarian has an unprecedented opportunity for significant innovative practice.

\section{REFERENCES}

Baker, Betsy (1989). Bibliographic instruction: building the Librarian/Faculty partnership. Reference librarian 24, 311-328

Bloom, B.S. (Ed.) (1984). Taxonomy of educational objectives: the classification of educational goals. NY: Longman.

Breivik, Patricia Senn (1989). Politics for closing the gap. Reference librarian 24, 5-16.

Brookfield, S. (1987) Developing critical thinkers. San Francisco: Jossey-Bass.

Brundage, D.H. and Mackeracher, D. (1980). Adult learning principles and their application to program planning. Toronto: Ministry of Education.

Burge, Elizabeth J. and others. (1989). Developing partnerships: an investigation of library-based relationships with students and educators participating in distance education in Northern Ontario. Toronto: Ontario Institute for Studies in Education. ED 311902.

Burge, Elizabeth J. (1991). Relationships and responsibilities: librarians and distance educators working together. Off Campus Library Services Conference, Albuquerque, New Mexico. ED 339383. Burge, Elizabeth J. and Roberts, Judith M. (1998). Classrooms with a difference: facilitating learning on the information highway. $2^{\text {nd }}$ ed. Montreal: McGraw Hill.

Carr, David (1986). The meaning of the adult independent library learning project. Library trends 35, 327-345.

Darkenwald, G.G. and Merriam, S.B. (1982). Adult education: foundations of practice. NY: Harper and Row. 
Doyle, Christina S. (1992). Final report to National Forum on Information Literacy. ED 351033 Ennis, Robert (1987). A taxonomy of critical thinking dispositions and abilities. In Joan B. Baron and Robert J. Sternberg (Eds.) Teaching thinking skills: theory and practice. New York: W.H.Freeman and Co., 1987.

Galbraith, M. W. (1989). Essential skills for the facilitator of adult learning. Lifelong learning: an omnibus of practice and research 12, 6, 10-13.

Galbraith, M.W. (1991). Facilitating adult learning: a transactional process. Malabar: Robert E. Kreiger.

Gibb, J.R. (1960) “Learning theory in adult education. In M.S. Knowles (ed.) Handbook of adult education in the United States. Washington, D.C.: Adult Education Association of the U.S.A. Gibson, Craig (1989). Alternatives to the term paper: an aid to critical thinking. Reference librarian 24, 297-309.

Hensley, Randall (1991). Learning style theory and learning transfer principles during reference interview instruction. Library trends 39, 3, Winter, 203-209.

Huston, Mary and Oberman, Cerise (1989) Making communication: a theoretical framework for educating end users of online bibliographic information retrieval systems. Reference librarian 24, 199211.

Keenan, Lori (1989). Andragogy off-campus: the library’s role. Reference librarian 24, 147-158 Kidd, J.R. (1973). How adults learn. NY: Cambridge Books.

King, David and Baker, Betsy (1987). Human aspects of library technology: implications for academic library user education. In Mellon, Constance A. (Ed). Bibliographic instruction: the second generation. Littleton: Libraries Unlimited.

Knowles, M. (1980). The modern practice of adult education: from pedagogy to andragogy. N.Y.: Cambridge. Knowles, M. (1990). The adult learner: a neglected species. $4^{\text {th }}$ ed. Houston: Gulf Publishing. 
Knox, A. B. (1977). Adult development and learning: a handbook of individual growth and competence in the adult years. San Francisco: Jossey-Bass.

Knox, A.B. (1986). Helping adults learn. San Francisco: Jossey-Bass.

Lancaster, F.W. (1972). Evaluation of online searching in MEDLARS (AIM-TWX) by biomedical practitioners. University of Illinois Graduate School of Library Science Occasional papers 101.

MacAdam, Barbara and Kemp, Barbara (1989). Bibliographic instruction and critical inquiry in the undergraduate curriculum. Reference librarian 24, 233-244.

Mackeracher, D. (1996), Making sense of adult learning. Toronto: Culture Concepts.

Miller, H.L. (1964). Teaching and learning in adult education. NY: Macmillan.

Oberman, Cerise and Linton, Rebecca A. (1982). Guided design: teaching library research as problemsolving. In Oberman, Cerise and Strauch, Katina (Eds.) Theories of bibliographic education: designs for teaching. NY: Bowker.

Oberman, Cerise (1991). Avoiding the cereal syndrome, or critical thinking in the electronic environment. Library trends 39, 3, Winter, 189-202.

Shapiro, Jeremy J. and Hughes, Shelley K. (1996). Information technology as a liberal art: enlightenment proposals for a new curriculum. Educom review 31, 2, March/April, 31-35. Sheridan, Jean (1986). Andragogy: a new concept for academic librarians. Research Strategies 4, 4, 156-167.

Simpson, E.L. (1980). Adult learning theory : a state of the art. In H.Lasker, J.Moore, and E.L. Simpson (eds.) Adult development and approaches to learning. Washington, D.C. , National Institute of Education.

Smith, R.M. (1982). Learning how to learn: Applied learning theory for adults. NY: Cambridge Books. Tuckett, Harold W. and Stoffle, Carla J. (1984). Learning theory and the self-reliant library user. $R Q$ 24, Fall, 58-65. 
Wilson, Vicky (1994). Developing the adult independent learner: information literacy and the remote external student. Distance education 15, 254-279. 